\title{
RECOGNITION AND ADAPTATION OF CLIMATIC AREAS IN CHAHARMAHALAND BAKHTIARI PROVINCE OF IRAN IN TERMS OF TOURISM CLIMATE COMFORT
}

\author{
Mohsen Abbasnia ${ }^{13}$, Mahnaz zarabi14, Ali Hossein Zadeh ${ }^{15}$, Amin \\ Hasannejad ${ }^{16}$
}

\begin{abstract}
Climatic phenomena play a significant role in development of the tourism industry. An appropriate climate may bring positive responses of tourists. The tourists plan their journeys considering the climatic and weather conditions of their destination. Chaharmahaland BakhtiariProvince is a mountainous region in west of Iran which enjoys various distribution of climatic elements especially rainfall and temperature due to topographic diversity. Statistical methods of factor analysis and cluster analysis were applied to obtain a precise recognition about the climatic zones of the province. 26 climatic variables were selected from six existing weather stations in the province. The results obtained from factor analysis showed that province climate is affected by four climatic factors which are listed here in order of significance: rainfall factor, serene sky factor, thermal factor and humidity factor. Then, four climatic regions were distinguished in the province by means of cluster analysis that was administrated on matrix of factor grades. At last, using PET index, evaluation and comparison were carried out for climate comfort at stations representing each climatic region during a year. The results revealed that May was the best month in terms of climate comfort conditions. Thermal stresss began from June and reached their peaks in July and August. Boroujen and Kouhrang stations entered the climate comfort range in September while same conditions happened for Shahr-e-kord and Lordegan in October.
\end{abstract}

KEY WORDS: climate segmentation, chaharmahaland Bakhtiari province, factor analysis, cluster analysis, PET climate comfort index

JEL: Q54

UDC: 338.483.11:551.58(55)

COBISS.SR-ID 272196108

\footnotetext{
${ }^{13}$ Department of Meteorology, Istanbul Technical University,MaslakIstanbul Turkey, e-mail: abbasnai@itu.edu.tr

${ }^{14}$ Department of Assessment and spatial planning, Payamnoor university of Tehran, Iran, email:mahnaz.zarabi@gmail.com

${ }^{15}$ Department of Environmental, University of Tehran, e-mail: ali.hossin.zadeh@ut.ac.ir

${ }^{16}$ Department of Environmental, University of Tehran
} 


\section{INTRODUCTION}

Nowadays, influence of climatic and weather conditions on life, health and comfort of human being and also on development of tourism industry is studied as a scientific branch named human ecological climatology (Ezatian, Momenzade, 2011). Being the main context of human activities, recognition of natural potentials is known as a basement for ecological and spatial planning. In this regard, climate segmentation and recognition of effective elements for each region are helpful to define climate features of the regions. Nowadays, complete success of developing plans for tourism, agriculture, industry, irrigation projects, transportation, sanitation, etc. may be achieved when they are accompanied with recognition of climate areas and use of their various potentials.

Chaharmahaland Bakhtiari Province is a mountainousregion in Iran Plateau with a 2150metre altitude that extends from 31 degrees and 9 minutes to 32 degrees and 38 minutes northern latitude and from 49 degrees and 30 minutes to 51 degrees and 26 minutes eastern longitude. Various land reliefs and high mounts with western winter air masses crossing the province have led to creation of some different small climates (Zende del, 1997, p 23). Also, this province is an interesting destination for tourists due to its historical and artistic monuments and its appropriate weather during the year. However, this important tourism destination seems to be developed in recent decades with no codified plans or attention to its natural and climatic potentials. It may reach a sustainable development by proper planning in tourism industry. For this purpose, it is necessary to investigate the appropriate time and place for each region to prepare itself for tourists after that all characteristics of climatic regions were entirely recognised.Segmentation of local phenomena has a long history in geography. The necessity of segmentation may be distinctively seen in climatology (Alikhani, 2000, p221). In the past, conventional methods were applied for climatic segmentation. In 1909, Copen became the pioneer in the field who offered an important climatic segmentation method with only taking temperature and rainfall annual averages into account (Ganji, 2003, p40). Thenceforth, conventional and single-variable methods were gradually replaced with multi-variable statistical techniques, principal component analysis and clustering which are used for climatic segmentation. Puvanswaran criticised climatic segmentations in which one- or two-variable methods and declared that as a multi-variable phenomenon, climate segmentation has to be performed through multi-variable statistical methods. The ability to increase or decrease the climates of a certain region was mentioned as benefit of multi-variable methods (Puvanswaran, 1990, p591).

Steiner study in 1965 was a premier in the field of new statistical methods appliance. He determined climatic regions of the U.S. by investigating sixteen climatic parameters. Other researchers (Newnham (1968), Ehrendorfer (1987), Bunkers et al. (1996), Fovel (1999), Bjoern et al. (2010) and Yons (2011)) have widely used these methods to reduce variable sides and recognise climatic regions. There are numerous researches in the climatology literature of the world which are performed using these methods. Climatological studies in Iran were mostly based upon conventional and single-variable methods while multi-variable statistical analyses have been used since recent two decades. For instance, Heidari and Alijani (1999, p57) distinguished three perpendicular factors (humidity, temperature and wind direction) using 49 climatic variables in 43 weather stations over the country(1963-1990) by decomposition methods. Considering the mentioned factors values, the surveying stations were categorised by Ward's clustering decomposition method and it was concluded that this method is acceptably in accordance with Iranian topographic units. In another research, Masoudian (2003, p176) characterised six climatic factors (thermal, humidity and cloud, rainfall, wind, mist and thunder) using 27 climatic variables in 120 weather stations over the country; then, Iran was divided into 15 climatic regions using the clustering method. GeramiMotlagh and Shabankari (2006, p188) in an article titled as climatic segmentation of Bushehr Province proved that the most important 
constituent factors of the province climate were: the wind-humidity factor, the rainfall-cloud factor, the thermal-vision factor and the wind-mist factor. In result, these climatic factors divided Busheher Province into five climatic regions. Also, Salighe and Esmailnejed (2008, p188) managed to divideSistan and Balouchestan Province into five climatic regions using five climatic factors. In another research, the obtained results from factor and cluster analyses on climatic segmentation in Isfahan Province revealed that usage of new multi-variable method for exact recognition of major creating factors of weather regions led to more trusty data for future investments in various scientific divisions rather than conventional single-variable methods (Amir Ahmadi and Abbasnia, 2010, p56). In the newest research, Hashemi et al (2015) were prepared the zoning maps of tourism climate comfort across the Zanjan province by using of GIS. Thus, acquaintance with natural features of each region, especially the weather, may be of importance in planning and investment. Studies on relation of the climate impact on tourism industry have not been wide; however, history of such researches goes back to 50s. At that time, the attempts were concentrated to estimate the comfort conditions of man by using mathematical and statistical relations and graphs and also by means of climatic factors such as temperature, humidity, wind speed, etc. (Sari Saraf et al. 2010, p101). According to the definition, thermal comfort condition is called a range in which temperature adjustment mechanism of human body stays at minimum (Giovni, 1976, p28). Thus, tourism industry plays an important role in development of the regions as is known as the main source of income, business, growth of the private sector and development of infrastructures. Many factors influence tourism expanse that an important one is the climatic conditions of the destination which is highly considered. In fact, weather and tourism industry are mutually dependent; in other words, the weather may act both as a restricting factor and a definitive one for tourism industry (Shackleford and Lecha, 1997, p46), (Shackleford and Olsson, 1995, p239). The best method to reveal the appropriate time for touring is using the climate comfort indices. Mieczkowsi (1985, p220) defined tourism climate comfort index using seven climatic factors and assessed climatic desirability for tourists. Zolfaghari (2007) characterised the proper touring time for Tabriz by means of PET and PMZ indices and also determined a 45-day climatic comfort period for the city from early May till midJune, a 240-day coldnessstress period from late September till mid-April and an 80-day heat stress from mid-June till mid-September. There have been many investigations about effects of ecological climatic indices on human comfort conditions using different methods which may refer to Mohammadi and Saeidi (2009), Qanbari et al. (2010), Esmaeili et al. (2010), Barimani and Esmaeilnejad (2011), Ataei and HashemiNasab (2011), Deb et al. (2010) and Ping Lin et al. (2011).In this field, MansouriDaneshvar et al $(2013,59)$ in a study over Iran showed that the PET index is one of suitable thermal index In compliance with climate of Iran.

These days, weather has the leading role in development and construction planning of a region and climatic conditions of a place is a significant parameter which most of the tourists take into consideration for choosing their destination. In this study, according to the fact that climate comfort investigations about recognition of effects of weather conditions on tourism capabilities of various regions of the country has been rare;it was primarily tried to perform climatic segmentation for Chaharmahaland Bakhtiari Province by means of new factor and cluster analyses methods and secondarily assess the best time and place for tourists visit during the year using PET climate comfort index for each city representing an extractive climatic region of the province. 


\section{MATERIALS AND METHODS}

Firstly, an exact recognition of small existing climatic regions in Chaharmahaland Bakhtiari Province was achieved by means of multi-variable statistical methods and geographical intelligence system. Surfer, Spss, ArcGis and Excel was used during different stages of the study. Hence, annual average values of 26 climatic variables (precipitation more than 1,5 and $10 \mathrm{ml}$, average dry temperature, average of minimum and maximum of temperature, temperature profile range, minimum and maximum of absolute temperature, water vapour pressure, surface pressure at stations, snow and sleet, frost, vision less than $2 \mathrm{Km}, 7-8$ octa cloudy sky, serene sky, number of rainy days, temperature more than $21^{\circ} \mathrm{C}$, average relative humidity, minimum and maximum of relative humidity, sunny hours, maximum daily rainfall, total annual rainfall, average wind speed and misty days) obtained from 6 weather stations and was used after analysing and removing faults. Weather stations conditions are demonstrated in table 1.

Table 1: the weather stations of the province conditions

\begin{tabular}{cccccc}
\hline Station & Type & Altitude & Longitude & Latitude & $\begin{array}{c}\text { Duration of } \\
\text { statistical } \\
\text { period }\end{array}$ \\
\hline Borujen & Synoptic & 2197 & 51.18 & 31.57 & $1988-2005$ \\
Kouhrang & Synoptic & 2285 & 50.07 & 32.26 & $1987-2005$ \\
Lordegan & Climatology & 1580 & 50.49 & 31.31 & $1995-2005$ \\
Shahr-e-kord & Synoptic & 2061 & 50.51 & 31.53 & $1995-2005$ \\
Edalat & Synoptic & 2323 & 50.56 & 31.53 & $1972-2005$ \\
Zaman Bridge & Climatology & 1810 & 50.54 & 32.29 & $1964-2005$ \\
\hline
\end{tabular}

\section{(Courtesy of Iranian organization for meteorology)}

Due to topographic diversity and lack of testifying stations throughout the province and to cover all of the area accurately with climatic variables of the province, IDW interpolation method was used. In this method, a net with proper mesh size is spread over the area and climatic elements values are estimated in nodes. Data obtained from the stations are used as testifier to assess degree of certainty of node data. Since in IDW interpolation method (reverse distance) it is assumed that sample points have weighted effects and are affected by place; in other words, the nearer place pixels to sample points are more affected by these points rather than further place pixels; then, the reverse distance interpolation method was used for segmentation.

By means of IDW interpolation method, 26 climatic elements were expanded to the area of 46 nodse. So that, the distance between each node was $20 \mathrm{~km}$ and $6 \times 26$-matrix (variables $\mathrm{x}$ stations) was altered to a 46x26-matrix (variables x nodes). The later correlation matrix was used as the input factor analysis model with an $\mathrm{R}$ array. Factor analysis consistingof some statistical techniques aims to simplify complex data groups. In this method, the correlated climatic variables are combined together considering the internal correlation and a new variable named as major element or factor is obtained. Equation 1 demonstrates the factor analysis pattern: 


$$
\begin{aligned}
& \mathrm{x}_{1} \mu_{1}=\mathrm{l}_{11} f_{1}+\mathrm{l}_{12} f_{2}+\ldots \mathrm{l}_{1 m} f_{m}+\varepsilon_{1} \\
& \mathrm{x}_{2} \mu_{2}=\mathrm{l}_{21} f_{1}+\mathrm{l}_{x_{1} \ldots x_{n} 22} f_{2}+\ldots \mathrm{l}_{2 m} f_{m}+\varepsilon_{2} \\
& . . \mathrm{x}_{p} \mu_{p}=\mathrm{\iota}_{p 1} f_{1}+\mathrm{l}_{p 2} f_{2}+\ldots \mathrm{l}_{p m} f_{m}+\varepsilon
\end{aligned}
$$

Equation 1

Decomposition of the correlation matrix of area data in spss gives factor grades matrix on nodes with dimensions of 46x4 (factors $\mathrm{x}$ nodes) and factor loads matrix on variables with dimensions of $26 \times 4$ (factors $x$ variables). The whole set of these matrices shows that which group of climatic elements have a greater impact on climate creation in different divisions of the province. Mostly, the final results of factor analysis are used as raw data for clustering method (Alikhani, 1381). Next stage is to answer that how many climatic regions were there in the province which is carried out by means of Ward's clustering method in a hierarchical way. Therefore, the nodes were categorised using the cluster analysis on factor grades matrix. In this method, grouping of observations is done according to the distance among them i.e. the observations with less distance are placed in the same group. The distance is measured by Euclidean geometry. Firstly, degree of dissimilarity is calculated by measuring the Euclidean distance among the climatic elements of all place points of matrix P (Equation 2) and then, clusters that merging them together gives minimum variance and diffraction values would be merged.

$$
d_{r s}^{2}=\left(p_{r}-p_{s}\right)\left(p_{r}-p_{s}\right)
$$

Equation 2

$d_{r s}^{2}$ is the Euclidean distance between the point (or group) $r$ with coordinates of $(\varphi r, \lambda r)$ and point (or group) $s$ with coordinates of $(\varphi s, \lambda s), p_{r}$ is the climatic variable of point (group) $r$ and $\mathrm{p}_{\mathrm{s}}$ is the climatic variable of point (group) $\mathrm{s}$.

In other words, there is same number of clusters and observations in the beginning of the clustering process while all observations would summed through one cluster in the final stage.

Afterwards, in order to recognise the tourism climate comfort features of each region, the representative station of each region was investigated in terms of $\mathrm{PET}^{17}$ index. It is an important thermophysiological index which is derived from energy balance of the human body (Hoppe, 1999, p72):

$$
\mathrm{M}+\mathrm{W}+\mathrm{R}+\mathrm{C}+\mathrm{E} \mathrm{D}+\mathrm{E} \mathrm{Re}+\mathrm{E} \mathrm{Sw}+\mathrm{S}=0 \quad \text { Equation } 3
$$

Where $\mathrm{M}$ is metabolism rate of body, $\mathrm{W}$ is output of physical work, $\mathrm{C}$ is convection heat flow, $\mathrm{R}$ is pure radiance of body, ED is the evaporative latent heat flow of water from skin, ERE is total effective thermal flows in heating, evaporation and transpiration and ESW is the flow of effective air in evaporation and body transpiration.

All of the terms are expressed in Watts and M has usually positive while ESW, ED and W have negative values. If the human body is gaining energy, the equation gives a positive answer; however, if the human body is losing energy the answer would be a negative value. The categorising numeric thresholds of the index with descriptive status of physiological and thermal stress conditions are given in table 2. Since, calculations are very time-consuming and complicated;after that necessary conversions were made on climatic factors (temperature in Celsius, relative humidity percentage, wind speed in $\mathrm{m} / \mathrm{s}$ and cloudiness in octa), then, daily data was given to the software as Rayman model input the output associated to monthly categorisation of PET index for each station representing a climatic region was obtained according to the thermal sensitivity during a year. According to defined thresholds in table 2 , if the index value was between 18 and 23, the tensionless physiological period is set in the region and values more than 23 would cause heat stresses and values less than 18 would lead to coldness stresses. Accordingly, diverse conditions may be observed throughout the province during a year.

17- Physiologic Equivalent Temperature 
Table 2: Values of PET index threshold at different degrees of human sensitivity

\begin{tabular}{ccc}
\hline Physiological stress degree & Thermal sensitivity & PET \\
\hline Extremely intensive coldness stress & Very cold & $<4$ \\
Intensive coldness stress & Cold & 4 \\
Intermediate coldness stress & Cool & 8 \\
Low coldness stress & Slightly cool & 13 \\
No coldness stress & Convenient & 18 \\
Low heat stress & Slightly warm & 23 \\
Intermediate heat stress & Warm & 29 \\
Intensive heat stress & Hot & 35 \\
Extremely intensive heat stress & Very hot & 41 \\
\hline
\end{tabular}

\section{STUDIES ON CLIMATIC FACTORS OF CHAHARMAHALAND BAKHTIARI PROVINCE}

Factor analysis with basic and rotational components $\left(\right.$ Warimax ${ }^{18}$ ) showed that 26 climatic elements of the province may be divided into 4 factors according to their internal correlation. The summation of these factors expresses about 97.8 per cents of variance values of the entire data. Thus, these factors play a significant role in formation of the climate of the province. After major factors had been recognised, spatial analysis maps of factors were plotted to determine degree of predominance of each factor for each part of the province after major factors had been recognised.

\section{FIRST FACTOR- RAINFALL}

This factor illustrates 37.6 per cents of total variance of data. Therefore, it is the most important factor in climate of a region. Precipitation, cloudiness and poor vision are the most effective variables for the first factor. Sunny hours, average of dry temperature, average of maximum temperature and misty days show reverse relationships towards this factor. The major dominance of rainfall factor was observed in western and north-western parts of the province and it was reduced with heading towards the East (figure 1).

\section{SECOND FACTOR- SERENE SKY}

This factor shows 21.9 per cents of total variance of data and has a straight relation with serene sky and temperature above $21^{\circ} \mathrm{C}$ variables. The most dominant region of this factor was seen in southern parts especially Lordegan station (figure 2).

\footnotetext{
18- In this type of rotation, the rotary pattern is headed to a situation in which only few variables throw large eight on factor and other variables have approximately no weight. (Durencomp, 1991, p158)
} 


\section{THIRD FACTOR-THERMAL}

This factor represents 20.9 per cents of total variance of data and thermal variables have the most weights on it. Rainfall, frost and average wind speed show reverse relations. The dominant region of this factor was Zamankhan Bridge and Lordegan stations and it was weakly seen in Edalat station (figure 3).

\section{FOURTH FACTOR-HUMIDITY}

Possessing 17.3 per cents of total variance of data, humidity is the last effective factor in climate of the province. Maximum, minimum and average of relative humidity have a straight relation with this factor; while, average of dry temperature, sunny hours and wind speed demonstrate reverse relationship. This factor was dominantly observed in Zamankhan, Edalat and Shahr-e-kord stations (figure 4).

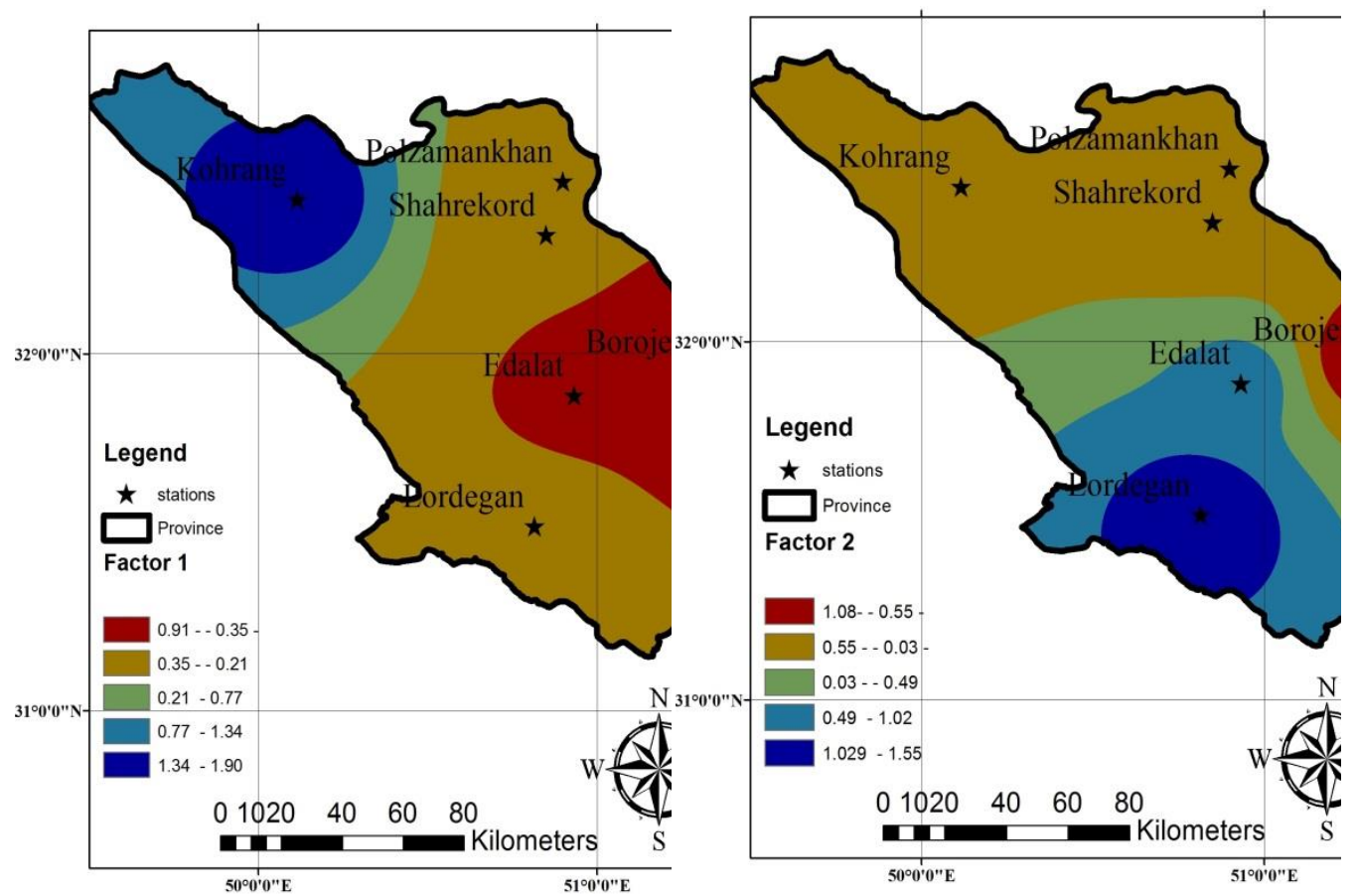

Figure 1: Spatial analysis of the first factor (rainfall)
Figure 2: Spatial analysis of the second factor (serene sky) 


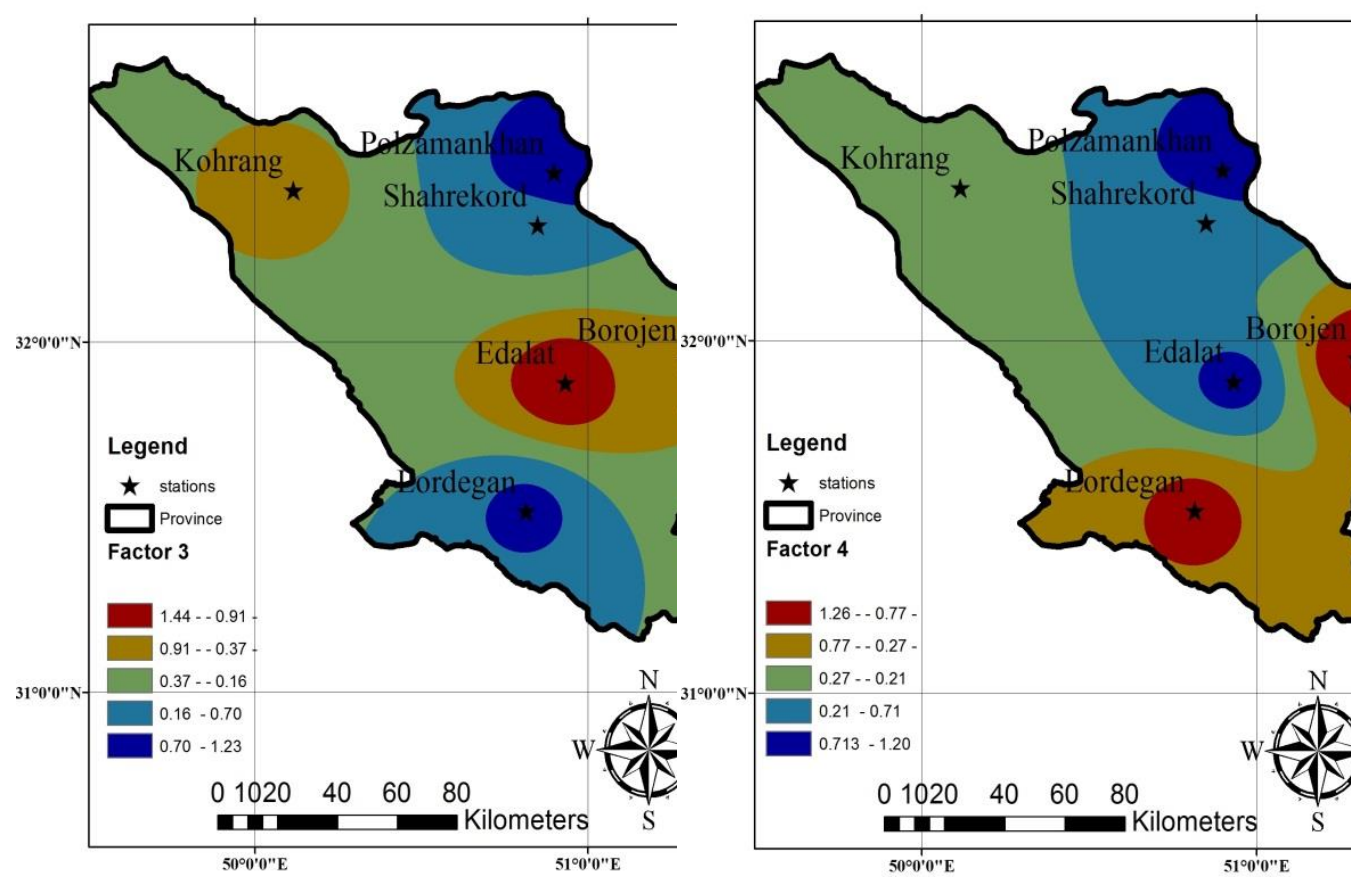

Figure 3: Spatial analysis of the third factor (thermal)
Figure 4: spatial analysis of the forth factor (humidity)

\section{THERMAL COMFORT CONDITIONS OF CLIMATIC REGIONS IN CHAHARMAHALAND BAKHTIARI PROVINCE}

By means of Ward's clustering method (clustering based on distance), the stations were categorised according to the factor grades. Figure 5 shows the clustering tree and cluster interceptions which distinguished four climatic regions.

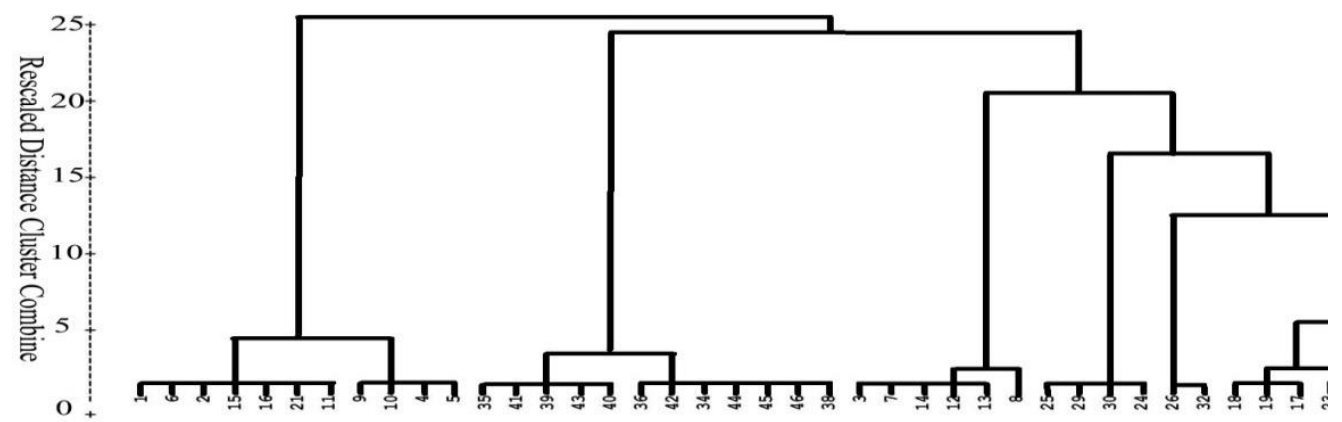

Figure 5: Tree diagram of climatic regions of Chaharmahaland Bakhtiari Province 
After that it was revealed each node belongs to which climatic group, the results were given to GIS software and climatic regions map was plotted (figure 6). Neighbouring nodes were placed mostly in same groups and coveredintegrated spatial domains. So that, boundary of climatic areas became distinct.

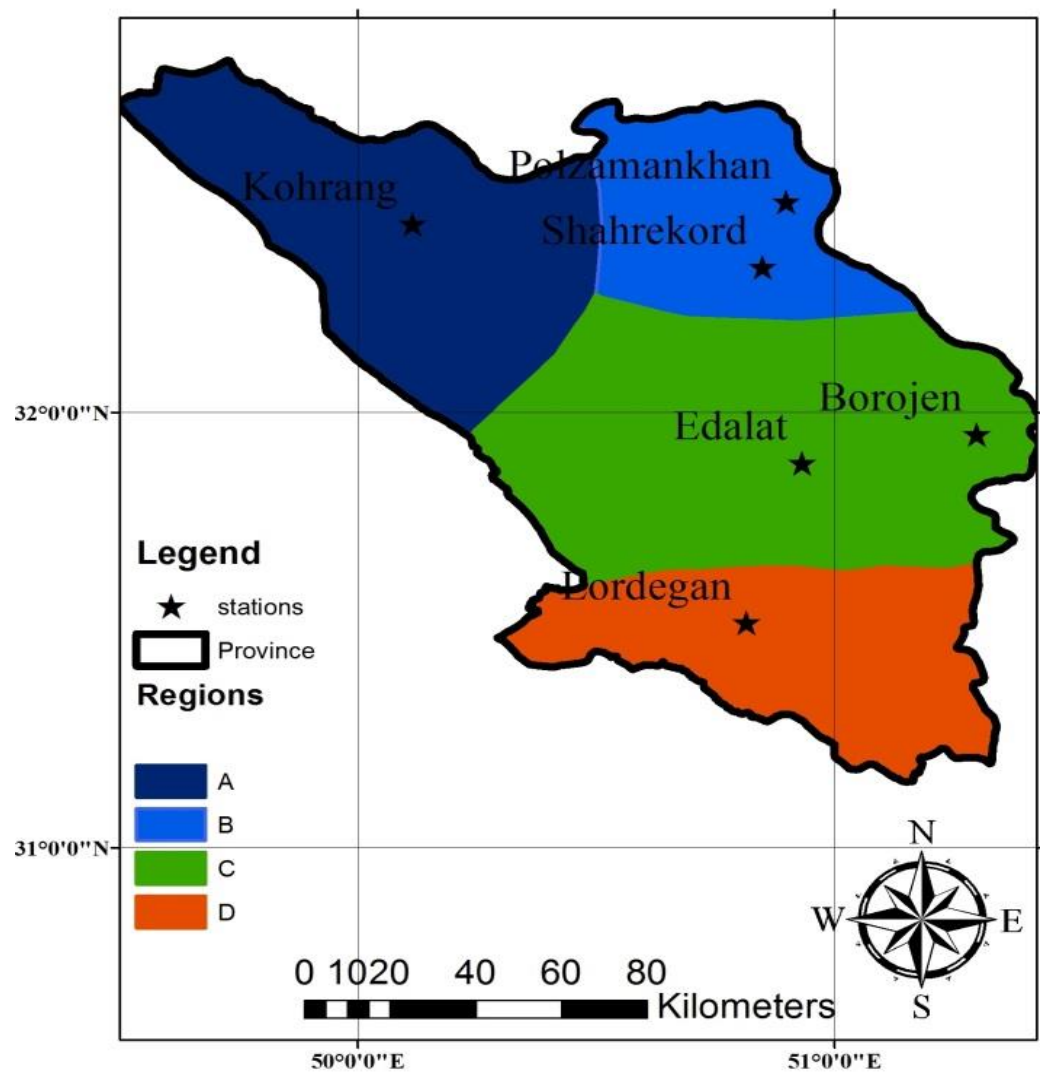

Figure 6: Extractive climatic regions of Chaharmahaland Bakhtiari Province

Eventually, each station representing a region was studied in terms of ecological climatic and thermal comfort conditions using PET index results after designation based on existing climatic and topographic features.

\section{a. Semi-mountainous and semi-wet region (representing station: Shahr-e-kord)}

This is the smallest region of the province including a tiny area in north-eastern parts. Thermal and humidity factors are highly seen in this area. Hence, a very various situation may be seen in Shahr-e-kord during a year in terms of climatic and tourism comfort conditions. Coldness stresses are dominant in January, February and March with different degrees. It is necessary to note that coldness intensity decreases since March. There are no physical tensions in May and then different degrees of heat stress may be seen which start in June, peak in July and August and end in September. No tension status again may happen in October and after November, coldness tensions increase till December and then (figure 7.a) 


\section{b. Mountainous and wet region (representing station: Kouhrang)}

The main characteristic of this region is extreme precipitation. Then, this factor has the most spatial dominance in the region. The average altitude is 2285 metres. Being mountainous and consequently cold, Kouhrang station experiences the highest number of frosty days during a year in the province (about 130 days).

PET calculations for Kouhrang showed that intense coldness sensitivity is dominant during January, February and March that this station experiences the coldest weather in the province. After March, coldness intensity decreases so that in May, comfort conditions are observed in the region. After all, weather tends to warmness and thermal sensitivity reaches its peak in July and August. No stress condition happens again in September (figure 7.b).

\section{c. Warm, wet and moderate region (representing station: Lordegan)}

The most dominant factors are serene sky and temperature while humidity acts weakly. Therefore, high temperatures and serene sky are major features of this plain region. PET index outputs for Lordegan are the same as Shahr-e-kord. This city enjoys a complete normal situation and perfect for touring during May and October. The mere difference is about coldness tensions in autumn and winter which are not very hard. This fact may be considered for winter journeys (figure 7.c).

\section{d. Cold, semi-wet and moderate region (representing station: Boroujen)}

This is the largest climatic region of the province which includes central, western and eastern parts. Then, climatic diversity is seen in the distance among plains and mountains of the region. Precipitation factor has the least effect on climatic features. It means that this region experience less rainfall in comparison with other regions. Recording 129 frosty days a year, Boroujen station is the coldest spot of the region. PET index results showed that May and September are the only months being in tensionless status. The city does not experience intensive heat stresses during a year which has to be considered by associated authorities (figure 7.d).
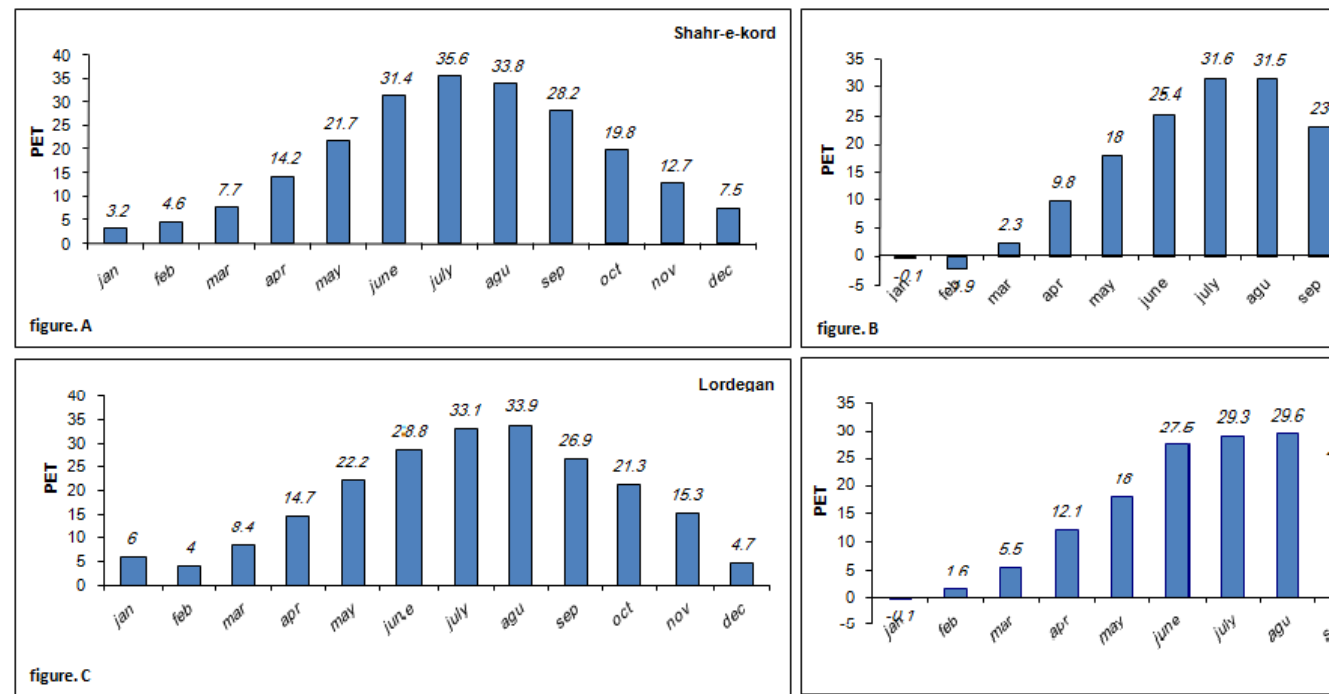

Figure 7: Monthly classification of PET index based on thermal sensitivity for stations representing each climatic region 


\section{CONCLUSIONS}

Human beings have always been interested in experiencing the climatic conditions of various parts of the world. Although, Chaharmahaland Bakhtiari Province is uniformly affected by certain synoptic conditions in atmospheric multi-scale systems; however, due to diversity of local factors and especially topographical diversity, it enjoys many small climates and heterogeneous climatic areas. Therefore, it was tried to recognise these small climatic regions by means of multi-variable statistical methods. Four major climatic factors (precipitation, serene sky, temperature and humidity) were recognised after factor analysis on 26 climatic elements. The rainfall factor having 37.6 per cents of total variance of data has the most effective role among all of extractive climatic factors in the province. So that, climatic differences are very sensible with increase or decrease in rainfall in western and north-western parts of the province due to existence of distinguished mountains and being exposed to western mass rains. Overall, these extractive factors were used to justify 97.8 per cents of climatic behaviour of Chaharmahaland Bakhtiari Province. Four distinguished climatic areas were identified after determination of spatial domains of factors by means of Ward's clustering method and. Then, the representative stations were investigated in terms of thermal and tourism comfort conditions by PET index. The PET results for stations are similar that all of them experience coldness intensities in winter. The situation undergoes reduction after April. May was chosen as the best time in terms of climate comfort conditions. Heat stresses start from June and reach their peaks in July and August. Boroujen and Kouhrang stations entered the climate comfort range in September while same conditions happened for Shahr-e-kord and Lordegan in October.

In conclusion, by recognition of effective climatic factors at any point and adapting them with PET climatic comfort index results, it is possible to inform the tourists where to go and when the perfect time is. Other practical benefits of PET index are: consideration of all climatic aspects that affect tourism industry e.g. thermal and physiological sides, being a combination of climatological, tourism and bioclimatic aspects, capability of estimation of index values for future touring months and periods and practicability for tourism industry users. These days, the positive effects of tourism in tourism-ecological point of view may attract people, authorities and even international organisations to some areas in order to preserve them.

\section{REFERENCES}

1. Alijani, B. (2000). Climate of Iran, Payam-e-noor University publications.

2. Alijani, B. (2002). Synoptic climatology, Semat publications.

3. Amir, A. A.,Abbasnia, M. (2010). Climatic segmentation of Isfahan Province using new statistical methods, Journal of geographic studies on dry areas, No.1, pp53-68.

4. Ataei, H., Hasheminasab, S.(2011). Assessment and segmentation of tourism climate of Isfahan Province using PET index and geographic intelligence system, Articles book of the first tourism management and stable development in centrality of tourism, a connector for cultures (TMSD), Islamic Azad University of Marvdasht, p27.

5. Barimani, F., Esmaeilnejad, M. (2011). Study on ecological climatic indices affecting tourism season (case: southern Iran), Geography and development, No. 23, pp27-46.

6. Bjoern H., Bobertz, B.,Harff, J. ( 2010). Classification of the Pearl River Estuary via Principal Component Analysis and Regionalization. J. Coastal R, 26(4): 769-779.

7. Bunkers, M.J,. Miller, J.R,Dagestano, A.T. (1996). Definition of climate regions in the Northern plains using objective cluster modification techniques. J. Climate, 9,PP:130-146. 
8. Deb ,Ch. Ramachandraiah, A. (2010). Evaluation of thermal comfort in a rail terminal location in India, Building and Environment, volume 45,pp 2571-2580.

9. Dorencomp, K., Farifte, J. (1991). Quantitative analyses on geomorphology, University of Tehran publications.

10. Ehrendorfer M. (1987). A regionalization of Austria's precipitation climate using principal component analysis. J. I. Climatology, 7,PP: 71-89.

11. Esmaeili, R., Saber, H.A., Malbousi, S. (2010). Evaluation of comfort conditions of Chahbahar for tourism development, Articles book of 4th international congress of Islamic world geographers, Zahedan, Iran, pp1-9.

12. Ezatian, V., Momenzade, F. (2011). Assessment of tourism climate of Mazandaran Province using TCI index, Tourism and stable development summit, Islamic Azad University of Hamedan, pp1-13.

13. Fovel R. G.,Fovel M. C. (1993). Climate zones of coterminous United States defined using cluster analysis. J. Climate, 6: 2103-2135.

14. Ganji, M. H. (2003). Climatic divisions of Iran, Journal of Literature and Humanisms Faculty, University of Tehran, No.1, pp27-72.

15. Gerami, M.A., Shabankari, M. (2006). Climatic segmentation of Bushehr Province, Research journal of Isfahan University (humanisms), No.1, pp-187-210.

16. Ghanbari, A.,Afifi, M. E., Sadeghi, G. (2010). Assessment of man comfort in city of Lar according to ecological climatic index, Quarterly-journal of natural geography, Year three, No. 10, pp93-109.

17. Givoni B. (1976). Man, Climate and Architecture. 2nd edition: Applied Science Publishers, Elsevier press, Univercity of Waterloo Canada, New York, USA.

18. Hashemi, S. R., Ardavan, B., Nazari, A. A. (2015). Assessment and Zoning of Tourism Comfort Climate of Zanjan Province using TCI Index, International Journal of Review in Life Sciences, 5(3), 811-822.

19. Heydari, H., Alijani, B. (1999). Climatic classification of Iran using multi-variable statistical techniques, Quarterly-journal of geographic researches, No.37, pp57-74.

20. Hoppe, P.(1999).The Physiological Equivalent Temperature-a Universal Index for the Biometeorological Assessment of the Thermal Environment. Int. J.Biometeorology 43:71-75. Lecha L. shackleford p. (1997), Climate services for tourism and recreation. WMO Bulletin,PP 46-49.

21. Mansouri Daneshvar, M. R., Bagherzadeh, A., Tavousi, T. (2013). Assessment of Bioclimatic Comfort Conditions based on Physiologically Equivalent Temperature (PET) using the RayMan Model in Iran, Central European Journal of Geosciences, 5(1), 53-60.

22. Masoudian, A. (2003). A study on precipitation distribution in Iran by means of rotated factor analysis, Journal of geography and development, Year one, No.1, pp176-194.

23. Mieczkowski, Z. (1985). The tourism climatic index: A method of evaluating world climates for tourism. Canadian Geographer, 29,PP: 220-233.

24. Mohammadi, H., Saeidi, A. (2008). Effective ecological climatic indices for man comfort assessment, case study: City of Qom, Journal of Ecology, Year thirty four, No.47, pp73-86.

25. Newnham, R. M. (1968). A Classification of Climate by Principal Component Analysis and Its Relationship to Tree Species Distribution. J. F. Sci, 14(3) ,PP: 245-264. 
26. Ping Lin, T. Matzarakis, A. (2011). Tourism climate information based on human thermal perception in Taiwan and Eastern China, Tourism Management,volume 32,pp 492-500.

27. Puvanneswaran, M. (1990). climatic classification for Queensland using multivariate statistical technique .International Journal of Climatology, 10,PP: 591-608 .

28. Salighe, M., Esmaeilnejad, M. (2008). Climatic segmentation of Sistan and Baluchestan Province, Journal of geography and development, No.12, pp110-116.

29. Sari Sarraf, Behrouz et al. (2010). Climatourism segmentation of Arasbaran area using TCI index, Journal of geographical space, Year ten, No. 30, pp63-88.

30. Shackford P. Olsson L. (1995). Tourism, climate and wether, WMO Bulletin 44,PP: 239-242.

31. Stiner, D (1965). A multivariate statistical approach to climatic classification, Tidschrift van het koninklijkNederlandschAardrijkskundiggenootschp, 82:pp:329-347.

32. Yunus F. (2011). Delineation of Climate Divisions for Peninsular Malaysia, Geospatial World Forum, Dimensions and Directions of Geospatial Industry, Hyderabad, India.

33.Zende del, Hassan et al. (1998). A comprehensive collection for visiting Iran: Chaharmahaland Bakhtiari Province, Irangardan publications.

34. Zolfaghari, H. (2007). Determination of appropriate time for visiting Tabriz using PET and PMV indices, Geographical studies, No.62, pp-129-141.

\section{Article history:}

- Received 24 September 2018

- Accepted 1 December 2018 